\title{
Integralidade, construção e socialização de conhecimentos no contexto da educação permanente e atuação de profissionais da área da saúde*
}

Os diversos cenários que se apresentam atualmente em serviços de saúde no Brasil, especialmente quando se tratam de instituições públicas, mostram-se complexos e desafiadores para os profissionais inseridos em suas equipes. As demandas são intensas e a realidade permeada de dificuldades diversas, como a insuficiência de recursos humanos e materiais, questões socioeconômicas vivenciadas pelos diferentes atores deste contexto, entre outros.

Mesmo diante destas questões, inúmeros profissionais, especialmente no contexto da saúde pública, apesar dos problemas que se apresentam, desempenham suas atividades de modo a oferecerem aos usuários dos serviços o melhor atendimento. Buscam, portanto, formas de superar as dificuldades ou minimizar os transtornos, auxiliando pacientes a obterem o que vem sendo considerado como "qualidade de vida" e empregando, para isto, todo o tempo disponível para suas atividades profissionais. Assim, ainda que muitas ações governamentais venham sendo delineadas para reforçar a importância e necessidade da formação permanente dos atores inseridos nos serviços de atenção à população na área da saúde, em consonância com a Política Nacional de Educação Permanente em Saúde (Brasil, 2009), a sobrecarga de trabalho dificulta a participação destes em cursos, seminários, palestras, entre outros. E as exigências do cotidiano levam estes profissionais a, muitas vezes, estabelecerem a prática como prioridade, relevando, a segundo plano, as atividades de capacitação, qualificação ou atualização. Quando envolvidos com estas, entretanto, estes sujeitos normalmente colocam-se na posição de alunos, não ocupando, em relação ao saber construído na área da saúde, o lugar de protagonistas. A reflexão sobre a prática fica, pois, muitas vezes, restrita ao movimento individual de cada profissional, e o tempo exíguo dificulta um pensar coletivo sobre a realidade do serviço e desafios que se colocam no atendimento ao paciente.

No meio acadêmico, o cenário que caracteriza o contexto da saúde no país, com seus problemas e características, também convoca pesquisadores, gerando estudos sobre o tema, desenvolvidos com o intuito de buscar conhecer a realidade que se apresenta e, quando possível, solucionar as dificuldades observadas. Entretanto, embora desenvolvidas por profissionais com grande experiência e conhecimentos propiciadores de investigações científicas de inegável qualidade, estas pesquisas, muitas vezes, demonstram um viés gerado pelo olhar de atores

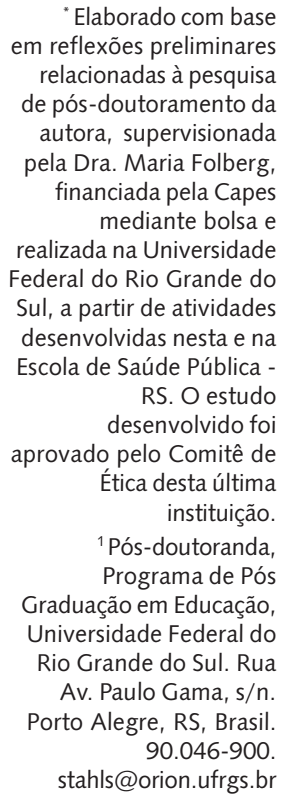

"Elaborado com base em reflexões preliminares relacionadas à pesquisa de pós-doutoramento da autora, supervisionada pela Dra. Maria Folberg, financiada pela Capes mediante bolsa e realizada na Universidade Federal do Rio Grande do Sul, a partir de atividades desenvolvidas nesta e na Escola de Saúde Pública RS. O estudo desenvolvido foi aprovado pelo Comitê de Ética desta última instituição.

1 Pós-doutoranda, Programa de Pós Graduação em Educação, Universidade Federal do Rio Grande do Sul. Rua Av. Paulo Gama, s/n. Porto Alegre, RS, Brasil. 90.046-900

stahls@orion.ufrgs.br 
externos ao cotidiano dos serviços e, portanto, eventualmente, desconectados dos detalhes da prática desenvolvida nos mesmos e dos desafios do dia a dia.

Como sabemos, a dissociação entre fazer e saber é uma das características predominantes da ciência moderna, fortemente marcada pela concepção de pesquisa como fruto de investigações de sujeitos neutros e, preferencialmente, não relacionados ao objeto de estudo (Capra, 1982). Como lembra Morin (2000), estas concepções têm, entre outras consequências, a cisão entre sujeito, tema da filosofia, e objeto, relacionado à pesquisa e a ciência. Neste contexto, a divisão entre sujeitos que fazem, ou seja, os profissionais inseridos nos serviços, e sujeitos que pesquisam, isto é, investigadores normalmente vinculados à academia, se justifica e valida, como relevantes, prioritariamente, os saberes construídos no meio universitário (Santos, 2004).

Diante destas observações, faz-se imprescindível considerarmos, brevemente, as implicações da inserção das pesquisas e práticas profissionais nos diferentes paradigmas científicos que orientam a construção de saberes na área da saúde ao longo dos tempos. Cabe estabelecer que, ao utilizarmos este conceito, partimos das proposições de Kuhn (2003), que descreve um paradigma como um conjunto de crenças, valores e ideias compartilhados pelos membros de uma comunidade científica, para nos determos, em seguida, nas ideias sobre o termo formuladas por Morin (1996), que o enriquece ao considerar, em suas concepções, a noção de relação. O autor afirma que um paradigma "comporta um certo número de relações lógicas, bem precisas, entre conceitos, noções básicas que governam todo discurso" (Morin, 1996, p. 287), considerando, ainda, que estas inter-relações determinam o curso das teorias e discursos inseridos neste conjunto de ideias. Concordando com as proposições estabelecidas por este pensador, cabe ainda mencionarmos as considerações sobre o termo formuladas por Capra (1982), que considera, na história do pensamento ocidental, a existência de dois grandes paradigmas: o mecanicista, moderno, e o sistêmico, que poderíamos relacionar à pós-modernidade.

Como observam Pinheiro e Luz (2007), a racionalidade moderna que orienta o pensamento científico é caracterizada pela fragmentação do conhecimento em seu objeto e sujeito, isto é, a natureza e o homem, que passa a ser concebido como conjunto de diferentes peças que podem ser analisadas separadamente.

Estabelecido como herança de proposições cartesianas, o paradigma moderno, ao segmentar teorias e práticas, gera, também, uma importante cisão do atendimento ao paciente e da pesquisa em múltiplas especialidades (Capra, 1982), responsáveis pela atenção aos processos do corpo ou do psiquismo, muitas vezes não integrados em uma percepção do paciente como sujeito concebido em sua integralidade. Conceito que, como lembra Pinheiro (2009), tem, como um de seus sentidos, um atendimento ao paciente que não se reduza à compreensão dos processos biológicos envolvidos na doença, mas que seja pautado pela escuta e consequente percepção das necessidades mais amplas do sujeito no que diz respeito a sua saúde. Complementando estas ideias, Pinheiro e Luz (2007) afirmam, ainda, que a integralidade implica uma ação social possibilitada pela articulação democrática entre os diferentes atores envolvidos em práticas de saúde, que podem ser construídas e reconstruídas no cotidiano das instituições. O que coloca a integralidade não apenas na categoria de princípio, mas, também, como direito e serviço oferecido nas mesmas.

Entretanto, embora a integralidade seja um dos princípios doutrinários do Sistema Único de Saúde SUS (Brasil, 1990), ações desenvolvidas junto ao paciente, em um contexto de demanda intensa e dificuldade de estabelecer espaços de reflexão coletiva, acabam, muitas vezes, evidenciando práticas segmentadas pelos conhecimentos das diversas especialidades, não integradas no atendimento ou compreensão de cada questão que se apresenta.

Neste contexto, o psiquismo, por exemplo, é entendido como atribuição da Psicologia e da Psiquiatria, enquanto a outras áreas da Saúde, como Enfermagem, Medicina, Fonoaudiologia e Fisioterapia, cabe enfocar a eliminação das enfermidades do corpo. Com frequência, tais concepções desconsideram a articulação entre aspectos orgânicos, psíquicos e sociais na etiologia das patologias tema com que se preocuparam profissionais da saúde desde a época de Hipócrates - e percebem como irrelevantes as implicações do funcionamento psíquico nos processos de adoecimento, especialmente evidenciadas pela Psicanálise e, em especial, nos trabalhos de Freud (1898/1996a; 1914/1996b; 1917/ 1996c). O pai da Psicanálise, como lembra Traverso-Yépez (2001, p.50), demonstrou o “papel de 
conflitos emocionais na aparição de sintomas que não mostravam nenhuma causa física imediata". Ao não se preocuparem com as relações e intersecções de diferentes aspectos do ser humano em seus processos de adoecimento e cura, tais modos de intervenção desconsideram, como ressalta Capra (1982, p.135), que "o estado psicológico de uma pessoa, evidentemente, não só é importante na geração da doença, mas também crucial para a cura".

Apesar da revalorização, nas últimas décadas, de concepções que apontam para a inter-relação entre aspectos sociais, psíquicos e orgânicos na etiologia de transtornos entendidos como orgânicos e psíquicos - surgindo novas demonstrações da articulação entre os mesmos através de inúmeros trabalhos e pesquisas (Sibemberg, 2005; Jerusalinsky, 1999; Laznik-Penot, 1997; Winnicott, 1990) tanto profissionais ditos da área "psi" quanto aqueles cuja atribuição diz respeito aos cuidados com o corpo ainda se mostram, muitas vezes, incapazes de conceber o ser humano como todo indivisível, que compreende aspectos referentes a diversas áreas, que se interligam e influenciam mutuamente.

O crescente descontentamento das populações diante da insuficiência do atendimento estabelecido a partir deste paradigma vem gerando, como ressalta Capra (1982), reflexões sobre o mesmo e busca de novas possibilidades de atuação e concepções de atenção em saúde, que o autor associa à emergência do paradigma sistêmico, mais capaz de considerar as relações entre os fenômenos e menos preocupado em segmentar para compreender. Diante deste desafio, mostra-se fundamental a formação de profissionais capazes de estabelecer práticas alicerçadas em um novo paradigma de saúde, trabalhando para uma abordagem integrada de ser humano, onde há uma ressignificação do enfoque sobre patologias, alvo de diferentes especialistas, para noções como prevenção e promoção de saúde.

Czeresnia (2003) diferencia os dois conceitos acima mencionados, assinalando que as ações relacionadas à prevenção "definem-se como intervenções orientadas a evitar o surgimento de doenças específicas, reduzindo sua incidência e prevalência nas populações" (p.45) - discurso referenciado pelos conhecimentos epidemiológicos modernos e cujo objetivo é, sobretudo, a redução do risco ou o controle de transmissão de doenças. Projetos de prevenção em saúde estruturam-se, portanto, por meio de divulgação sobre informações científicas, bem como recomendações sobre mudanças de hábitos que poderiam evitar o surgimento das doenças. Já a promoção de saúde mostra-se um conceito mais amplo, pois visa não apenas evitar doenças, mas enfatizar processos que podem favorecer a saúde e o bemestar. As estratégias de promoção de saúde, portanto, enfocam "a transformação das condições de vida e de trabalho que conformam a estrutura subjacente aos problemas de saúde" (Czeresnia, 2003, p.45).

A autora ressalta, ainda, que, no contexto da sociedade capitalista neoliberal, a perspectiva conservadora de promoção de saúde serve à noção da importância do fortalecimento dos sujeitos e grupos sociais, enfatizando uma concepção de autonomia que serve à desresponsabilização do Estado em relação a estes. Já perspectivas progressistas, enfatizam outra dimensão da promoção de saúde, ressaltando a importância da formulação de políticas públicas intersetoriais, cujo objetivo seja a melhoria de qualidade de vida dos sujeitos e comunidades.

Promover a saúde alcança, dessa maneira, uma abrangência muito maior do que a que circunscreve o campo específico da saúde, incluindo o ambiente em sentido amplo, atravessando a perspectiva local e global, além de incorporar elementos físicos, psicológicos e sociais. (Czeresnia, 2003 p.40)

A construção e aceitação de um paradigma em saúde cujos pressupostos abarquem a concepção progressista de promoção de saúde e sua incorporação na prática dos profissionais das diferentes áreas de atenção, tornando-os capazes de estabelecer novos posicionamentos diante do paciente, entretanto, certamente demanda transformações na visão dos mesmos sobre sua prática e seu papel na sociedade em que atuam.

Tais transformações nas concepções dos profissionais sobre ciência e mundo, com importantes implicações em sua prática, não são possíveis sem a existência de um importante processo de reflexão e, mesmo, a construção de novos paradigmas educacionais, voltados tanto para a formação presente nos cursos de graduação quanto nas atividades de educação permanente, como cursos de curta duração e pós-graduação, sobretudo lato sensu, uma vez que os chamados "cursos de especialização" atendem, prioritariamente, profissionais inseridos em espaços diversos do mercado de trabalho. 
Morin (2000, p.25) salienta, em relação à Educação, que é necessário "desenvolver nova geração de teorias, abertas, racionais, críticas, reflexivas, autocríticas, aptas a se auto-reformar", objetivo que podemos considerar imprescindível em todas as áreas de intervenção junto ao ser humano.

Reforçando estas concepções, Correia e Dias $(1998$, p.116) consideram que "os desafios que se colocam no futuro em termos educacionais exigem um novo paradigma, [...] que envolve aspectos tais como a prática profissional e os processos de desenvolvimento curricular".

No contexto das profissões que envolvem o cuidado ao ser humano em seus diversos enfoques, tais transformações, como salienta Capra (1982), só podem ser obtidas por meio da educação permanente em saúde, também reformulada a partir da necessidade de formar profissionais reflexivos, habilitados a integrar os conhecimentos construídos e articular sua área de intervenção a outras. Como aponta Batista (2004), profissionais capazes de se mostrarem tecnicamente competentes, buscarem a atualização através da educação permanente e atuarem em equipes multiprofissionais e interdisciplinares, respondendo às demandas sociais e possibilitando ao paciente um cuidado integral, pautado por uma atuação ética e compromissada com a sociedade.

Mostra-se essencial, portanto, que estudantes dos cursos de graduação e profissionais atuantes nos serviços priorizem a inclusão de atividades de educação permanente e espaços de reflexão entre suas ações, visando a qualificação do atendimento. Para que isto ocorra, é necessário, também, que estas atividades sejam priorizadas e viabilizadas pelos gestores, cuja ação mostra-se essencial, especialmente na busca de formas de permitir o afastamento temporário dos profissionais para a participação em cursos, seminários, encontros, entre outros.

A realização de atividades de formação continuada poderá garantir a qualificação constante e aprimoramento das práticas, visando o atendimento ao paciente pautado pela integralidade. A participação em espaços de reflexão sobre a prática poderá contribuir com este último objetivo, permitindo, ainda, a interlocução entre os diversos atores envolvidos na atenção aos sujeitos e, especialmente, a socialização das experiências desenvolvidas no enfrentamento aos desafios colocados pela realidade dos serviços de saúde brasileiros.

Se a socialização das experiências faz-se imprescindível para a qualificação do atendimento, observamos que não mostra longo alcance se não desenvolvida de forma a possibilitar a difusão dos saberes construídos. É fundamental, portanto, que estudantes e profissionais inseridos nos serviços possam buscar, também, modos de sistematizar suas experiências, articulando-as aos referenciais teóricos dos campos de conhecimento envolvidos, transformando-as em produção de saberes a serem divulgados a partir de formatos diversos, como encontros, seminários e textos.

Produzir conhecimentos, neste contexto, passa a ser não apenas privilégio de pesquisadores inseridos no meio acadêmico, mas, também, compromisso e possibilidade de todos os profissionais que desempenham suas práticas em contextos diversos dos serviços de saúde. Para que isso se mostre possível, entretanto, é necessário que seja rompida a cisão entre teoria e prática, concebendo ambas como articuláveis através da reflexão, sistematização e socialização de experiências desenvolvidas.

No contexto particular do serviço onde a autora vem desempenhando algumas de suas atividades profissionais ${ }^{2}$, a necessidade de criação destes espaços fez-se particularmente evidente no contato com alunos de cursos de especialização diversos da área da saúde. O contato com estes alunos, a maior parte profissionais com larga experiência em suas áreas de atuação, demonstrou 
que, a despeito de sua reconhecida competência, mostravam-se, muitas vezes, impossibilitados de reconhecer suas práticas como geradoras de saberes, percebendo a produção destes apenas no contexto acadêmico. No discurso destes sujeitos, permeado pelas concepções propagadas pelo paradigma cartesiano, fez-se particularmente perceptível a dificuldade em conceber uma prática a qual estavam tão intrinsecamente relacionados como capaz de gerar conhecimentos e teoria. A impossibilidade de neutralidade e a ausência de pesquisas formais abrangendo aspectos de suas práticas pareciam torná-las invalidadas do ponto de vista científico, já que atravessadas pelas implicações subjetivas inerentes à inserção na realidade vivenciada.

Buscando estabelecer um espaço de reflexão sobre este contexto e rompimento de alguns destes pressupostos, a autora propôs, em sua inserção na equipe docente destes cursos e da instituição à qual estavam vinculados, o desenvolvimento de oficinas de elaboração de artigos científicos.

Enquanto metodologia de ensino, segundo Anastasiou (2004), as oficinas podem ser entendidas como grupos de pessoas reunidas a fim de trabalharem e aprofundarem determinado tema, sob a orientação de um especialista, visando a aplicação de conceitos e conhecimentos através de atividades e com o objetivo de aprenderem a fazer melhor. No contexto da proposta aqui relatada, as oficinas vêm enfocando, em especial, a elaboração de relatos de experiência, proporcionando, aos envolvidos, atividades que têm como objetivo a aplicação prática de conhecimentos previamente construídos sobre a produção de textos. Inicialmente, em três versões consecutivas, a atividade foi oferecida como curso de extensão de 15 horas, distribuídas ao longo de dois meses, e voltadas para qualquer profissional interessado, oferecendo-se 15 vagas em cada turma. Foi incluída, também, entre as disciplinas oferecidas aos alunos do terceiro ano da Residência Integrada em Saúde, em uma das edições deste programa. Posteriormente, com carga horária de 15 a vinte horas, e realizada com turmas maiores, com aproximadamente 35 alunos, a proposta das oficinas foi integrada - como disciplina ou como parte do programa dos seminários de Metodologia em Pesquisa ou Pesquisa em Saúde - a alguns dos cursos de especialização oferecidos na instituição ou em parcerias desta com outros institutos de Ensino Superior e universidades, entre os quais os cursos de Especialização em Saúde Pública, Especialização em Direito Sanitário e Especialização em Gestão Hospitalar.

Partindo de atividades realizadas com o objetivo de conscientizar os participantes quanto à importância da socialização das práticas estabelecidas nos serviços em que estavam inseridos e de suas possibilidades de se colocarem como autores das mesmas em textos, descrevendo-as, o programa desenvolvido nas oficinas incluía temas como: processos de autoria, normas para elaboração de artigos, diferentes categorias possíveis de trabalhos e formas de submissão de manuscritos a periódicos. Eram oferecidas, ainda, muitas atividades práticas de elaboração de textos e adequação dos mesmos ao formato científico, sendo a interlocução entre os participantes e com a coordenadora parte essencial do processo vivenciado por cada autor, visto que possibilitava a constatação de sucesso na proposta de fazer de sua produção textual um instrumento de transmissão de experiências e saberes.

Embora com variações realizadas após as sucessivas versões que teve, a atividade considerou sempre, como foco, a conscientização sobre a importância da experiência prática e da formação em serviço, com discussões sobre a importância da busca de um novo paradigma em ciência e saúde, pautado pelo atendimento ao ser humano em sua integralidade. E, como ressalta Santos (2004), pela concepção da importância dos conhecimentos construídos no meio não acadêmico, articulando práticas e saberes destes decorrentes à produção acadêmica. A partir destas reflexões, as oficinas de elaboração de textos científicos buscaram, também, oferecer, aos participantes, instrumentalização sobre a elaboração de trabalhos passíveis de publicação nos meios de divulgação científicos. Por meio de observação e descrição de objetos, cenas e acontecimentos, e exercícios de registro de suas experiências no formato de textos científicos, os alunos puderam experimentar a transformação de suas vivências em artigos a serem enviados para submissão e possível publicação por periódicos diversos. Foram informados, ainda, sobre: algumas normas de elaboração de textos, formas de encaminhá-los para periódicos, critérios para aceitação ou rejeição de trabalhos, aspectos éticos de autoria e algumas políticas editoriais.

A experiência desenvolvida vem se mostrando uma forma interessante de rompimento com a cisão entre fazer e saber, proporcionando espaços de autoria e produção de conhecimentos para os alunos envolvidos. Neste sentido, faz-se importante também na valorização da experiência profissional dos 
mesmos, uma vez que podem se colocar não apenas como sujeitos que utilizam saberes produzidos por pesquisadores de outros contextos, mas, também, como autores de experiências que, ao serem sistematizadas e socializadas, podem ser valorizadas pela comunidade científica e aplicadas, também, por outros atores inseridos no contexto dos cuidados ao ser humano em sua integralidade. Neste sentido, Pinheiro e Luz (2007), ao abordarem o direito à saúde em sua concepção ampliada, lembram a importância de se considerar a integralidade como norteadora de novas formas de ação em saúde, capazes de permitir a criação de experiências inovadoras nos serviços, no contexto da incorporação e desenvolvimento de tecnologias assistenciais.

A realização das oficinas proporcionou, ainda, um espaço importante de reflexão sobre o fazer de cada sujeito participante, ao incentivar a interlocução entre profissionais oriundos de diferentes áreas de formação. Como salientam Luz e Pinheiro (2007), o ato de escutar e, ao mesmo tempo, proporcionar ao outro uma escuta, permite a valorização do gesto e a realização de ações que compreendam diferentes possibilidades e visões, tornando viável a concepção de um outro funcionamento do mundo.

As discussões realizadas nos encontros permitiram, portanto, uma maior articulação entre as áreas de atuação de cada profissional, contribuindo para um cuidado ao paciente pautado pela integralidade.

Por outro lado, na linha da valorização das experiências desenvolvidas e articulação das mesmas à produção de saberes, associando prática e teoria e a reflexão sobre as ações profissionais, as oficinas de elaboração de texto levaram a autora a interessar-se, especificamente, pela interlocução entre saberes e fazeres no contexto da formação e atuação na área da saúde. Desta forma, surgiu o interesse pela transformação destas reflexões e discussões em um projeto de pesquisa, fato que teve como efeito a decisão de realizar, enfocando esta temática, pós-doutorado, que vem sendo desenvolvido no Programa de Pós-Graduação em Educação da Universidade Federal do Rio Grande do Sul, sob supervisão da Dra. Maria Folberg.

Mostra-se fundamental a realização de ações que busquem o rompimento do modelo biomédico (Capra, 1982) - pautado pelo paradigma da modernidade e gerador de dissociação entre fazer e saber e um atendimento segmentado aos sujeitos que buscam os serviços de saúde. Como lembra Santos (2004), enfocando a formação universitária e, podemos pensar, importante também para a formação continuada e para a educação permanente em saúde, o modelo de ensino que adotamos deve ser pensado de forma articulada ao projeto de sociedade que queremos. Ações visando, também, a valorização das experiências desenvolvidas fora do contexto acadêmico, portanto, são fundamentais para que se possa formar profissionais qualificados a enfrentarem os desafios do contexto em que estão inseridos e, consequentemente, propiciarem aos sujeitos, junto aos quais desempenham suas atividades, um atendimento de qualidade, pautado pela noção de integralidade. Apenas desta forma poderemos, realmente, pensar na atuação profissional e no atendimento ao paciente no contexto da saúde pública como permeado pelos pressupostos da promoção da saúde em sua visão progressista. Logo, não apenas considerando a intervenção visando o desaparecimento da doença, mas também o modo de viver dos atores envolvidos nos processos relacionados à área da saúde, sejam pacientes que utilizam os serviços, ou sujeitos que nestes exercem suas atividades profissionais. 


\section{Referências}

ANASTASIOU, L.G.C.; ALVES, L.P. Estratégias de ensinagem. In: (Orgs.).

Processos de ensinagem na universidade: pessupostos para as estratégias de trabalho em aula. Joinville: Univille, 2004. p.67-100.

BATISTA, N.A. Planejamento na prática docente em Saúde. In: BATISTA, N.A.; BATISTA, S.H. (Orgs.). Docência em saúde: temas e experiências. São Paulo: Editora Senac São Paulo, 2004.

BRASIL. Ministério da Saúde. Secretaria de Gestão do Trabalho e da Educação na Saúde. Departamento de Gestão da Educação em Saúde. Política Nacional de Educação Permanente em Saúde. Brasília: Ministério da Saúde, 2009. Disponível em: <http:// portal.saude.gov.br/portal/arquivos/pdf/volume9.pdf>. Acesso em: 12 out. 2011.

Ministério da Saúde. Lei $\mathbf{n}^{\circ} \mathbf{8 . 0 8 0 / 9 0}$ - SUS. Dispõe sobre as condições para a promoção, proteção e recuperação da saúde, a organização e o funcionamento dos serviços correspondentes e dá outras providências. Brasília: MS, 1990.

CAPRA, F. O ponto de mutação: a ciência, a sociedade e a cultura emergente. São Paulo: Cultrix, 1982.

CORREIA, A.P.; DIAS, P. A evolução dos paradigmas educacionais à luz das teorias curriculares. Rev. Port. Educ., v.11, n.1, p.113-22, 1998.

CZERESNIA, D. O conceito de saúde e a diferença entre prevenção e promoção. In: CZERESNIA, D. et al. (Orgs.). Promoção da saúde: conceitos, reflexões, tendências. Rio de Janeiro: Fiocruz, 2003. p.39-53.

FREUD, S. La sexualidad en la etiologia de las neurosis (1898). In: Obras completas de Sigmund Freud. Madri: Biblioteca Nueva, 1996a. v.1. p.317-29. Introducción al narcisismo (1914). In: Freud. Madri: Biblioteca Nueva, 1996b. v.2. p.2017-023.

Duelo y melancolía (1917). In: Obras completas de Sigmund Freud. Madri: Biblioteca Nueva, 1996c. v.2. p.2091-100.

JERUSALINSKY, A. Psicanálise e desenvolvimento infantil. Porto Alegre: Artes e Ofícios, 1999

KUHN, T. A estrutura das revoluções científicas. São Paulo: Perspectiva, 2003.

LAZNIK-PENOT, M.-C. Poderíamos pensar numa prevenção da síndrome autística? In: WANDERLEY, D.B. (Org.). Palavras em torno do berço. Salvador: Ágalma, 1997

MORIN, E. Os sete saberes necessários à educação do futuro. São Paulo: Cortez, 2000.

Epistemologia da complexidade. In: SCHNITMAN, D.F. (Org.). Novos paradigmas, cultura e subjetividade. Porto Alegre: Artes Médicas, 1996. p.274-9.

PINHEIRO, R. Integralidade em saúde. In: FUNDAÇÃO OSWALDO CRUZ. ESCOLA POLITÉCNICA DE SAÚDE JOAQUIM VENÂNCIO (Org.). Dicionário da educação profissional em saúde. Rio de Janeiro: Fundação Oswaldo Cruz, Escola Politécnica de Saúde Joaquim Venâncio, 2009. Disponível em: <http://www.epsjv.fiocruz.br/ dicionario/verbetes/intsau.html?>. Acesso em: 15 out. 2011.

PINHEIRO, R.; LUZ, M.T. Práticas eficazes $x$ modelos ideais: ação e pensamento na construção da integralidade. In: PINHEIRO, R.; MATTOS, R.A. (Orgs.). Construção da integralidade: cotidiano, saberes e práticas em saúde. Rio de Janeiro: IMS/UERJ, Cepesc, Abrasco, 2007. p.9-36. 
INTEGRALIDADE, CONSTRUÇÃO E SOCIALIZAÇÃO ...

SANTOS, B.S. A universidade no século XXI: para uma reforma democrática e emancipatória da Universidade. São Paulo: Cortez, 2004.

SIBEMBERG, N. A prescrição de psicofármacos: um ato de fala em transferência. Correio Assoc. Psicanal. Porto Alegre, n.137, p.6-10, 2005.

TRAVERSO-YÉPEZ, M. A interface psicologia social e saúde: perspectivas e desafios. Psicol. Estud., v.6, n.2, p.49-65, 2001.

WINNICOTT, D.W. O gesto espontâneo: cartas selecionadas. São Paulo: Martins Fontes, 1990. 
O texto discute a fragmentação entre práticas desenvolvidas em serviços de saúde e saberes produzidos no contexto acadêmico, elaborando uma reflexão sobre o tema, enquanto fenômeno relacionado às concepções da ciência moderna, pautada pelo paradigma cartesiano. Discute a relevância de se estabelecerem novas concepções sobre a construção de conhecimentos, valorizando saberes desenvolvidos no cotidiano dos serviços e estabelecendo nova abordagem sobre o tema no âmbito dos cursos de graduação, pós-graduação e demais atividades realizadas dentro das propostas de educação permanente. Nesta perspectiva, é descrita uma experiência de realização de oficinas de elaboração de textos voltadas para profissionais que frequentam cursos de especialização na área da saúde, visando à sistematização e socialização de suas experiências. A atividade vem se mostrando um importante espaço de construção de saberes, permitindo que textos no formato de relatos de experiência sejam produzidos e divulgados nos meios científicos.

Palavras-chave: Integralidade. Saúde. Educação permanente. Oficinas de produção textual.

\section{Comprehensive health care, construction and socialization of knowledge in the context of permanent education and actions of health professionals}

The paper discusses the fragmentation between practices developed in healthcare services and knowledge generated in the academic context, proposing a reflection on the subject as a phenomenon related to the concepts of modern science, guided by Cartesian paradigm. It discusses the relevance of establishing new conceptions of building knowledge, valuing those elaborated in routine services and proposing a new approach about this subject in undergraduate and graduate courses, and also other activities within inservice education proposals. From this perspective it describes an experience in conducting workshops of texts elaboration, focused for professionals who are performing specialization courses in health area, aiming the systematization and socialization of experiences developed in their fields of professional activities. This activity allowed an important place in building knowledge and the elaboration of texts in the form of experience reports, published in scientific journals.

Keywords: Comprehensive health care. Health. In-service education. Textual production workshops.

\section{Integralidad, construcción y socialización de conocimientos en el contexto de la educación permanente y actuación de profesionales del área de la salud}

El texto discute la fragmentación entre las prácticas desarrolladas en los servicios de salud y saberes que se producen en el contexto académico, proponiendo una reflexión sobre el tema, como un fenómeno relacionado con los conceptos de la ciencia moderna, cartesiana. En este sentido, discute la importancia de establecer nuevas concepciones acerca de la construcción de conocimientos, valorando saberes elaborados en los servicios cotidianos y estableciendo nuevos planteamientos sobre el tema en los cursos de graduación, pos-graduación y actividades de educación permanente. Se describe una experiencia con talleres de elaboración de textos destinados a los profesionales que realizan cursos de especialización en salud, a fin de sistematizar y socializar sus experiencias. La actividad se viene mostrando un importante espacio de construcción de saberes, lo cual permite que textos científicos, en forma de relatos de experiencia, se produzcan y se divulguen.

Palabras clave: Integralidad. Educación permanente en salud. Talleres de producción textual. 
